\title{
TRANSLATION IDEOLOGY ANALYSIS OF PROPER NOUNS IN THE NOVEL PRIDE AND PREJUDICE BY JANE AUSTEN
}

\author{
Ayu Bandu Retnomurti \\ Universitas Indraprasta PGRI \\ Marmita Fiona \\ Universitas Indraprasta PGRI \\ Jalan Nangka no. 58 C Tanjung Barat, Jagakarsa, Jakarta Selatan \\ e-mail: ayubandu@gmail.com
}

\begin{abstract}
The research aims to describe translation ideology analysis of proper noun and to describe the types of translation ideology which occur in the novel Pride and Prejudice. The method used in the research is a qualitative comparative approach by comparing the translation of proper nouns in Source Language and Target Language. The results of the analysis show that the translator used foreignization ideology to transfer the meaning of the source text. The tendency is seen in the title of the text where the translator keeps the original title Pride and Prejudice instead of transferring into Harga Diri dan Prasangka. The type of translation ideologies occur in the novel are foreignization in which the translator stays faithful to the source language by preserving Mr. Darcy into Mr. Darcy, and domestication in which the translator stays closer to the target language by transforming The Bennets into Keluarga Bennet.
\end{abstract}

Key Words: Translation; Translation Ideology; Proper Noun; Novel

Article History: Received: 13/09/2020; Revised: 25/10/2020; Accepted: 15/11/2020; Published: 31/12/2020

How to Cite (MLA 7th): Retnomurti, Ayu Bandu, and Marmita Fiona. “Translation Ideology Analysis of Proper Nouns in The Novel Pride and Prejudice by Jane Austen." Hortatori Jurnal Pendidikan Bahasa dan Sastra Indonesia 4.2 (2020): 86-98. Print/Online. Copyrights Holder: Ayu Bandu Retnomurti, Marmita Fiona. First Publication: Hortatori Jurnal Pendidikan Bahasa dan Sastra Indonesia (2020).

This work is licensed under a Creative Commons Attribution-ShareAlike 4.0 International License.

\section{Pendahuluan}

Manusia dan bahasa adalah entitas yang tidak dapat dipisahkan. Sebagian besar aktivitas seharihari mereka menggunakan bahasa untuk menyampaikan maksud, keinginan, tujuan, dan niat terhadap orang lain. Sebagai sarana komunikasi, bahasa harus disusun oleh sistem, aturan, dan prinsip yang diterapkan dalam masyarakat. (Umam, 2015). Selain sebagai alat komunikasi, bahasa juga digunakan untuk mengungkapkan pikiran, gagasan, pesan, dan perasaan seseorang secara lisan atau tulisan (Eagleton, 2013). Salah satu contoh bahasa sebagai alat komunikasi dan cara mengekspresikan diri adalah melalui karya sastra, misalnya novel. Melalui novel, peneliti dapat mengkomunikasikan ide dan mengungkapkan pemikiran tentang segala hal (Devianty, 2017). Tidak semua pembaca memahami bahasa Inggris, oleh karena itu, layanan penerjemah tetap diperlukan Nida (dalam Nugroho, 2016). Dengan demikian, novel berbahasa Inggris yang diterbitkan biasanya diikuti dengan versi terjemahan dalam bahasa Indonesia.

Terjemahan adalah transformasi teks dari satu bahasa (Bahasa Sumber atau Bsu) ke bahasa lain (Bahasa Sasaran atau Bsa) tanpa mengubah makna teks aslinya (Munday, 2016). Ada dua pendapat berbeda tentang pengolahan budaya yang disebut domestication dan foreignization (Saraswati \& Dewanti, 2020). Menerjemahkan kata benda, terutama proper nouns meskipun dapat dikatakan sebagai salah satu aktivitas tersulit yang dihadapi penerjemah dalam menerjemahkan novel, karena selalu ada beberapa 
aspek tersembunyi di balik proper nouns yang ditulis oleh penulis dan terkadang sulit bagi penerjemah untuk menemukan padanan yang sesuai dalam Bahasa Sasaran (Lörscher, 2012). Untuk menghasilkan produk terjemahan yang akurat terutama pada terjemahan proper nouns, penerjemah memerlukan strategi atau teknik (Al Fattah \& Muamaroh, 2017).

Penelitian ini menjadi penting, karena peneliti menemukan berbagai macam Proper Nouns dalam novel Pride and Prejudice. Ideologi penerjemahan melalui Proper Nouns diterapkan dalam teks yang terbagi menjadi dua yaitu, foreignization, dan domestication. Berdasarkan latar belakang yang telah diuraikan di atas, maka permasalahan dalam penelitian ini adalah: Bagaimanakah analisis ideologi penerjemahan Proper Nouns dalam novel Pride and Prejudice beserta terjemahannya dan apa sajakah jenis-jenis ideologi penerjemahan yang terdapat dalam novel Pride and Prejudice. Oleh karena itu, penelitian ini berfokus pada Proper Nouns dalam teks novel Pride and Prejudice dan menganalisis strategi penerjemahan yang diterapkan pada masing-masing Proper Nouns (Venuti, 2018).

Penelitian ini menarik untuk dibahas, karena ideologi penerjemahan masih jarang dilakukan (Akbari, 2013), dan kecenderungan ideologi penerjemahan novel ini juga dapat dianalisis melalui strategi yang diterapkan dalam menerjemahkan Proper Nouns dan dianggap layak dianalisis (Dewi, 2016). Yang $(2014,322)$ menyatakan bahwa foreignization dan domestication adalah dua jenis cara penerjemahan yang sepenuhnya kontradiktif. Venuti $(2017,20)$ menjelaskan bahwa "Namun, kecenderungan tersebut menunjukkan kontras satu sama lain bahwa ada yang memercayai terjemahan yang baik adalah terjemahan yang memegang bahasa dan budaya sumber (foreignization), sementara yang lain percaya bahwa terjemahan yang baik harus menutup bahasa dan budaya sasaran (domestication)" (Nida dalam Yang, 2014, 320). Boase-Beier (2014) menunjukkan bahwa ideologi foreignization yang berorientasi pada bahasa sumber memiliki beberapa strategi penerjemahan berbeda dengan ideologi domestication. Farahani \& Mokhtari (2016) menjabarkan skema lain berdasarkan teori mereka seperti yang terlihat pada Gambar 1.

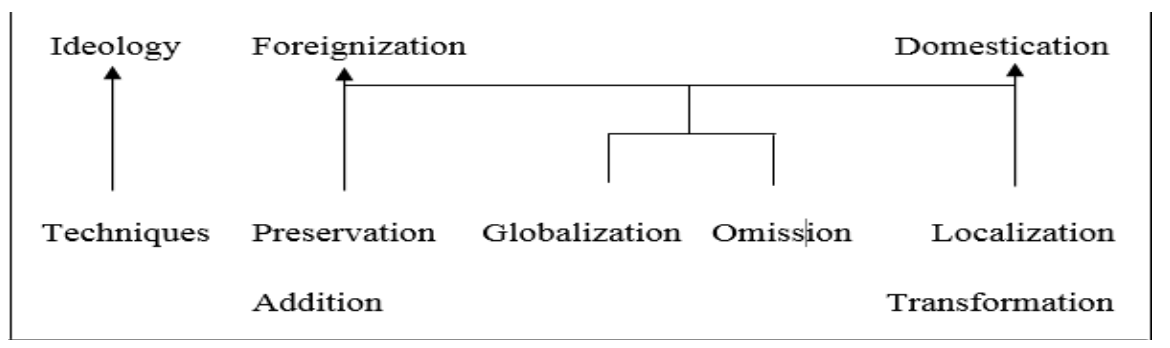

Gambar 1. A Kontinum antara Foreignization dan Domestication

Gambar 1 di atas menjelaskan bahwa ideologi yang digunakan oleh seorang penerjemah dapat dirunut dari teknik-teknik yang mereka terapkan. Skema tersebut menunjukkan bahwa teknik preservation dan Addition akan mengarah pada ideology foreignization, sedangkan teknik Localization dan Transformation akan mengarah pada ideologi domestication (Oittinen, 2014).

Proper nouns mengacu pada acuan khusus yaitu (Cascallana, 2014), berfungsi membedakan individu tertentu dari orang lain, misalnya, nama karakter dalam novel (Howard dalam Ningsih, 2016). Nama-nama karakter tersebut dalam istilah linguistik dikenal sebagai proper noun (O'Sullivan, 2013). Menurut Barnes (2013) mengatakan bahwa: "Proper noun diartikan sebagai nama individu atau individu yang hanya dibedakan dengan memiliki nama itu." Selain itu, O'Sullivan (2013) mengatakan bahwa nama asli fiksi dianggap sebagai penanda budaya di beberapa budaya karena penulis terkadang menemukan nama baru yang fantastis dalam budaya bahasa sumber (Zarei \& Norouzi, 2014). Jenis-jenis ini digunakan oleh Shiyab (2012) untuk memetakan proper nouns. Oittinen (2014) memercayai bahwa "proper nouns considered meaningless in real life and they usually only used only for signaling references". Strategi menerjemahkan lainnya dari proper nouns dinyatakan oleh Shirinzadeh et al. (2014) seperti: Preservation, Addition, Omission, Localization, Transformation, Globalization, Substitution, dan Creation. 


\section{Metode}

Metode yang digunakan dalam penelitian ini adalah kualitatif komparatif yaitu membandingkan teks dalam Bahasa sumber (Bsu) yaitu bahasa Inggris dan Bahasa Sasarannya (Bsa) yaitu bahasa Indonesia. Gunawan (2013) mendefinisikan kualitatif komparatif sebagai penelitian deskriptif yang bertujuan untuk menemukan jawaban mendasar tentang sebab dan akibat dengan menganalisis faktorfaktor penyebab atau kemunculan suatu fenomena tertentu. Teknik penelitian yang diterapkan dalam penelitian ini adalah mengumpulkan proper nouns dalam Bahasa Sumber (Bsu) dan versi terjemahannya dalam Bahasa Sasaran (Bsa) ke dalam jenis ideologi terjemahan yang telah ditentukan. Berdasarkan data yang sudah diklasifikasikan dan dianalisis, peneliti menyimpulkan bahwa ideologi dominan dari novel Pride and Prejudice apakah itu foreignization atau domestication. Untuk mempermudah proses klasifikasi, maka peneliti memberikan kode pada data berupa angka numerik, kategori SL (Bsu) atau TL (Bsa), dan halaman di mana data tersebut ditemukan.

\section{Hasil dan Pembahasan}

Ideologi terjemahan dapat dilihat dari strategi yang digunakan dalam menerjemahkan proper nouns. Ideologi penerjemahan digolongkan menjadi dua yaitu foreignization dan domestication. Berikut adalah hasil dan pembahasan dari ideology foreignisasi.

\section{Ideologi Foreignisasi}

Di bawah ini adalah ideologi terjemahan foreignisasi yang digunakan seperti, preservation. Elaborasi lebih lanjut disajikan sebagai berikut.

a. Foreignisasi melalui strategi Preservation

1) Netherfield Park

\begin{tabular}{|l|l|}
\hline \multicolumn{1}{|c|}{ Bsu } & \multicolumn{1}{|c|}{ Bsa } \\
\hline "My dear Mr Bennet," said his lady to him one day, "have "Suamiku Mr. Bennet tersayang," kata Mrs. Bennet kepada suaminya \\
you heard that Netherfield Park is let at last?" (03/SL- \\
A/P.1) & $\begin{array}{l}\text { pada suatu hari, "sudahkah kau mendengar bahwa akhirnya ada yang } \\
\text { menyewa Netherfield Park?" (03/TL-B/H.7) }\end{array}$ \\
\hline
\end{tabular}

Pembahasan:

Nama Netherfield Park digambarkan sebagai lingkungan tempat tinggal Tuan Bingley, teman karakter utama. Netherfield adalah Kota kecil di Inggris, oleh karena itu karena mengacu pada tempat nyata yang terletak di Inggris, maka tidak diterjemahkan. Namun, Parkin dalam bahasa sumber, menurut Oxford Mini Dictionary \& Thesaurus, mendefinisikan sebagai 1) taman umum di kota, 2) tanah tertutup dari rumah pedesaan, 3) area untuk tujuan tertentu, 4) area untuk parkir kendaraan. Melalui konteks dalam kalimat tersebut, makna Taman yang dimaksud mengacu pada definisi kedua yaitu "tanah tertutup rumah pedesaan" bukan sebuah taman atau Park, dengan demikian Netherfield Park yang dibahas dalam kalimat tersebut merupakan milik pribadi dalam bentuk tanah rumah pedesaan tertutup yang terletak di Netherfield. Mempertimbangkan konteks di atas, jadi penerjemah dapat menerjemahkan proper noun Netherfield Park menjadi Netherfield House, (Rumah Netherfield, diterjemahkan) yakni memiliki makna semantik yang sama, penerjemah memilih untuk tetap mempertahankan Netherfield dalam teks tersebut. Pandangan peneliti terhadap penerjemah dalam menerapkan strategi preservation pada proper nouns adalah tetap berpakem pada budaya sumber (Ningsih, 2016). Dengan demikian, strategi ini berpengaruh pada ideologi foreignization atau foreignisasi yang menyatakan bahwa terjemahan berterima dan baik adalah sesuai dengan selera dan harapan pembaca dengan menghadirkan budaya Bsu dan kehadiran Bsu memberikan manfaat untuk pembaca sasaran. Fenomena dan budaya asing seperti kata Netherfield dipertahankan untuk memberikan pengetahuan melalui foreignisasi. Foreignisasi juga digunakan untuk mempertahankan referensi budaya teks sumber, nilai - nilai budaya, dan sebagai pembelajaran lintas budaya (Yang, 2014, 328).

2) Mrs. Long

\begin{tabular}{|c|l|}
\hline \multicolumn{1}{|c|}{ Bsu } & \multicolumn{1}{|c|}{ Bsa } \\
\hline $\begin{array}{l}\text { "But it is," returned she; "for Mrs. Long has just been } \\
\text { here, and she told me all about it." (04/SL-A/P.1) }\end{array}$ & $\begin{array}{l}\text { "Tetapi itulah kenyataannya," jawab Mrs. Bennet, "karena Mrs. } \\
\text { Long baru saja dari sana dan dia menceritakannya kepadaku." } \\
(04 / \text { TL-B/H.7) }\end{array}$ \\
\hline
\end{tabular}


Pembahasan:

Data nomor 2, nama Mrs. Long dipertahankan oleh penerjemah. Ibu atau Nyonya dalam bahasa sumber berarti gelar untuk wanita yang sudah menikah dan memiliki padanan Mrs. (Nyonya, diterjemahkan) dalam bahasa sasaran. Di sisi lain, Long, dalam Kamus Oxford mendefinisikan sebagai 1) memiliki jangkauan yang besar atau tertentu dalam ruang atau waktu atau ukuran panjang tertentu, 2) pada waktu yang jauh. Jika penerjemah menerjemahkan makna Mrs. Long menjadi Nyonya Panjang, terjemahannya akan terdengar janggal dan tidak wajar dalam bahasa sasaran. Selain itu, mengingat sumber novel tersebut bukanlah karya sastra anakanak, keputusan penerjemah untuk tetap mempertahankan teks menjadi Mrs. Long tersebut adalah pilihan yang sangat baik (Ningsih, 2016). Preserving teks memberi efek ideologi foreignisasi.

\section{3) Michaelmas}

\begin{tabular}{|l|l|}
\hline \multicolumn{1}{|c|}{ Bsu } & \multicolumn{1}{|c|}{ Bsa } \\
\hline $\begin{array}{l}\text { "That he is to take possession before Michaelmas, and } \\
\text { some of his servants are to be in the house by the end of } \\
\text { next week." (09/SL-A/P.1) }\end{array}$ & $\begin{array}{l}\text { "Dia akan menempati tempat itu sebelum perayaan Michaelmas, dan } \\
\text { beberapa pelayannya akan tiba di sana pada akhir minggu depan." } \\
(09 / \text { TL-B/H.8) }\end{array}$ \\
\hline
\end{tabular}

Pembahasan:

Michaelmas, menurut Kamus Oxford, mengacu ke pesta St Michael pada 29 September. Michaelmas adalah Hari perayaan Suci hingga abad ke-18 dalam menghormati St. Michael, St. Gabriel, dan St. Raphael, serta hari libur ini tidak dikenal umum di bagian dunia lain. Karena perayaan tersebut tidak memiliki padanan yang cocok dan terdengar asing bagi bahasa sasaran, sehingga penerjemah memutuskan menggunakan strategi preservation untuk tetap mempertahankan istilah Michaelmas tersebut (Ningsih, 2016). Dengan demikian, ideologi foreignisasi ditemukan.

\section{4) Sir William}

\begin{tabular}{|l|l|}
\hline \multicolumn{1}{|c|}{ Bsu } & \multicolumn{1}{|c|}{ Bsa } \\
\hline $\begin{array}{l}\text { "Sir William and Lady Lucas are determined to go, "Sir William dan Lady Lucas sudah bertekat akan pergi hanya untuk } \\
\text { merely on that account, for in general, you know they visit } \\
\text { no newcomers. (12/SL-A/P.2) }\end{array}$ & $\begin{array}{l}\text { urusan itu; kau tahu sendiri biasanya mereka tidak pernah } \\
\text { mengunjungi pendatang baru." (12/TL-B/H.9) }\end{array}$ \\
\hline
\end{tabular}

Pembahasan:

Nama Sir William adalah salah satu nama tokoh dalam novel. Menurut Kamus Oxford, Sir digunakan sebagai cara sopan untuk memanggil seorang pria dan digunakan sebelum nama sebagai gelar ksatria atau Baronat. Oleh karena itu, makna Sir William dalam teks novel ini memiliki gelar yang tersirat dari status sosialnya. Istilah ini membuatnya sedikit di atas karakter lain dalam novel tersebut, oleh karena itu Sir William perlu dipertahankan dalam bahasa sasaran. Namun, akan terkesan membingungkan jika dialihkan ke bahasa sasaran karena tidak ada padanan yang cocok dalam bahasa sasaran untuk gelar terhormat ini. Dengan demikian, strategi preservation yang dipilih oleh penerjemah dirasa cocok untuk mempertahankan budaya sumber yang tersirat dalam nama tokoh tersebut (Ningsih, 2016). Di samping itu dapat memberikan kesan asing pada nama yang diberikan dalam bahasa sasaran, hal itu dianggap sebagai foreignisasi.

\section{5) Lady Lucas}

\begin{tabular}{|l|l|}
\hline \multicolumn{1}{|c|}{ Bsu } & \multicolumn{2}{|c|}{ Bsa } \\
\hline $\begin{array}{l}\text { "Sir William and Lady Lucas are determined to go, "Sir William dan Lady Lucas sudah bertekat akan pergi hanya untuk } \\
\text { merely on that account, for in general, you know they visit } \\
\text { no newcomers. (13/SL-A/P.2) }\end{array}$ & $\begin{array}{l}\text { urusan itu; kau tahu sendiri biasanya mereka tidak pernah } \\
\text { mengunjungi pendatang baru." (13/TL-B/H.9) }\end{array}$ \\
\hline
\end{tabular}

Pembahasan:

Nama Lady Lucas adalah salah satu nama karakter dalam novel. Menurut Oxford Mini Dictionary \& Thesaurus, Lady mendefinisikan sebagai 1) seorang wanita, 2) gelar yang digunakan oleh teman sebaya serta istri dan janda dari seorang ksatria, 3) seorang wanita yang santun. Merujuk pada definisi nomor 2 dari teks di atas, Lady Lucas adalah istri seorang ksatria yang dianggap memiliki status tinggi dalam suatu komunitas sosial. Oleh karena itu, Lady Lucas dalam novel ini memiliki panggilan yang tersirat dari status sosialnya. Panggilan ini membuatnya sedikit di atas karakter lain dalam novel, sehingga panggilan Lady Lucas perlu dipertahankan dalam bahasa sasaran. Namun, ini dapat membingungkan jika dialihkan ke bahasa sasaran karena tidak ada padanan yang cocok dalam bahasa sasaran untuk gelar terhormat ini. Dengan demikian, strategi preservation yang dipilih oleh penerjemah dirasa cocok untuk mempertahankan budaya 
sumber yang tersirat dalam panggilan nama tokoh tersebut (Akbari, 2013). Hal ini dapat memberikan kesan asing pada panggilan nama dalam bahasa sasaran tersebut dan dianggap sebagai foreignisasi.

6) Jane

\begin{tabular}{|l|l|}
\hline \multicolumn{1}{|c|}{ Bsu } & \multicolumn{1}{|c|}{ Bsa } \\
\hline $\begin{array}{l}\text { “...and I am sure she is not half so handsome as Jane, ” } \\
\text { (15/SL-A/P.3) }\end{array}$ & $\begin{array}{l}\text { “..kecantikannya tidak sampai separuh dari kecantikan Jane, } \\
(15 / \text { TL-B/H.10) }\end{array}$ \\
\hline
\end{tabular}

Pembahasan:

Data nomor 6, nama Jane merupakan salah satu nama tokoh dalam novel. Dia adalah saudara perempuan tertua dari karakter utama, Elizabeth Bennet yang ceritanya kemudian menjadi pemeran utama kedua dalam novel ini. Alih-alih penerjemah menggunakan strategi localization untuk menerjemahkan nama Jane sebagai Jeni dalam istilah terjemahan agar nama ini memiliki arti lokal dan lebih mudah diucapkan dalam bahasa sasaran, penerjemah menganggap preservation adalah strategi yang paling cocok untuk menjaga keaslian bahasa sumber (Akbari, 2013). Di sini dapat terlihat penerjemah ingin mengenalkan budaya sumber kepada pembaca sasaran agar mereka dapat merasakan dunia Jane Austen. Oleh karena itu, strategi yang dipilih oleh penerjemah yaitu memberi kesan asing atau foreignisasi pada teks dengan tetap mempertahankan istilah Jane pada teks tersebut.

7) Mary

\begin{tabular}{|l|l|}
\hline \multicolumn{1}{|c|}{ Bsu } & \multicolumn{1}{|c|}{ Bsa } \\
\hline $\begin{array}{l}\text { Mary wished to say something very sensible but knew not } \\
\text { how. (20/SL-A/P.5) }\end{array}$ & $\begin{array}{l}\text { Mary berharap bisa mengatakan sesuatu yang cerdas, tapi dia tidak } \\
\text { tahu harus berkata apa. (20/TL-B/H.14) }\end{array}$ \\
\hline
\end{tabular}

Pembahasan:

Nama Mary adalah salah satu nama tokoh dalam novel. Dia adalah saudara perempuan dari tokoh utama, Elizabeth Bennet. Alih-alih menggunakan strategi localization untuk menerjemahkan nama Mary sebagai Meri agar nama ini memiliki arti lokal dan lebih mudah diucapkan dalam bahasa sasaran, penerjemah menganggap preservation adalah strategi yang paling cocok untuk menjaga keaslian bahasa sumber (Akbari, 2013). Selain itu, penerjemah ingin memperkenalkan budaya sumber kepada pembaca sasaran agar mereka dapat merasakan dunia Mary. Oleh karena itu, strategi penerjemah yang dipilih ini memberikan kesan asing atau foreignisasi dengan tetap mempertahankan istilah Mary pada teks tersebut.

\section{8) Hertfordshire}

\begin{tabular}{|l|l|}
\hline \multicolumn{1}{|c|}{ Bsu } & \multicolumn{1}{|c|}{ Bsa } \\
\hline $\begin{array}{l}\text { She could not imagine what business he could have in } \\
\text { town so soon after he arrived in Hertfordshire. (21/SL- } \\
\text { A/P.7) }\end{array}$ & $\begin{array}{l}\text { Dia tidak mampu membayangkan urusan apa yang telah menanti Mr. } \\
\text { Bingley di kota segera setelah kedatangannya di Hertfordshire. } \\
\text { (21/SL-B/H.17) }\end{array}$ \\
\hline
\end{tabular}

Pembahasan:

Data nomor 8, Hertfordshire mengacu pada lingkungan tempat keluarga Bennets, Bingleys, dan Lucases tinggal. Meskipun lingkungan tersebut merupakan tempat imajiner yang diciptakan oleh Jane Austen, keberadaan tempat tersebut dianggap nyata dalam novel ini. Selain itu, nama tempat sebenarnya jarang diberikan dalam proses penerjemahan (Shirinzadeh et al., 2014). Karenanya, penerjemah memilih untuk tidak menerjemahkan nama itu dalam bahasa sasaran. Preservation dari proper noun terlihat dengan tetap mempertahankan istilah Hertfordshire dalam teks ini yang dapat memberikan efek ideologi foreignisasi.

\section{9) Derbyshire}

\begin{tabular}{|l|l|}
\hline \multicolumn{1}{|c|}{ Bsu } & \multicolumn{1}{|c|}{ Bsa } \\
\hline $\begin{array}{l}\text { And not all his large estate in Derbyshire could then save } \\
\text { him from having a most forbidding, [...]. (25/SL-A/P.8) }\end{array}$ & $\begin{array}{l}\text { Dan tanah luasnya di Derbyshire sekalipun tidak sanggup menutupi } \\
\text { perangai terburuknya. (25/SL-B/H.18) }\end{array}$ \\
\hline
\end{tabular}

Pembahasan:

Derbyshire mengacu pada lingkungan tempat tinggal Tuan Darcy. Meskipun lingkungan itu, dalam beberapa hal, adalah tempat khayalan yang diciptakan oleh Jane Austen, keberadaan tempat itu dianggap nyata dalam novel tersebut. Selain itu, nama tempat sebenarnya jarang diberikan dalam proses penerjemahan (Shirinzadeh et al., 2014). Karenanya, penerjemah memilih 
untuk tidak menerjemahkan nama itu dalam bahasa sasaran. Preservation dari proper noun terlihat dengan tetap mempertahankan istilah Derbyshire dalam teks ini yang dapat memberikan efek ideologi foreignisasi.

10) Miss King

\begin{tabular}{|l|c|}
\hline \multicolumn{1}{|c|}{ Bsu } & \multicolumn{1}{|c|}{ Bsa } \\
\hline $\begin{array}{l}\text { Then the two third he danced with Miss King. (34/SL- } \\
\text { A/P.10) }\end{array}$ & Setelah itu, dia berdansa dengan Miss King. (34/TL-B/H.22) \\
\hline
\end{tabular}

Pembahasan:

Data nomor 10, nama Miss King dipertahankan oleh penerjemah. Miss dalam teks sumber adalah istilah yang ditujukan untuk wanita yang belum menikah. Istilah ini memiliki padanan Miss (Nona, diterjemahkan) dalam bahasa sasaran. Di sisi lain, King, dalam Kamus Oxford diartikan sebagai penguasa laki-laki sebuah negara merdeka yang memiliki beberapa kerajaan. Padanan kata dalam bahasa sasaran adalah King (Raja, diterjemahkan). Jika penerjemah menerjemahkan makna Miss King menjadi Nona Raja, maka terjemahannya akan terdengar janggal dan tidak wajar dalam bahasa sasaran. Selain itu, teks akan diterjemahkan secara berlebihan karena maksud dari si penerjemah tidak tersampaikan, oleh sebab itu keputusan penerjemah untuk mempertahankan teks tersebut adalah pilihan yang sangat baik (Ningsih, 2016). Preserving istilah Miss King dalam teks ini dapat memberikan efek foreignisasi.

\section{Ideologi Domestikasi}

Di bawah ini adalah hasil dan pembahasan mengenai ideologi domestikasi yang terdiri dari lima strategi yaitu, globalization, omission, localization, transformation, dan creation. Namun seiring berjalannya penelitian, ada empat strategi dari lima yang ditemukan dalam penelitian ini. Elaborasi lebih lanjut disajikan sebagai berikut.

a. Domestikasi melalui Strategi omission

\begin{tabular}{l} 
1) The King \\
\begin{tabular}{|l|l|}
\hline \multicolumn{1}{|c|}{ Bsu } & \multicolumn{1}{|c|}{ Bsa } \\
\hline "Sir William Lucas had been formerly in trade in & "Sir William Lucas dahulu berdagang di Meryton. Disana, dia \\
Meryton, where he made a tolerable fortune, and risen to & mendapatkan cukup banyak kekayaan dan dianugerahi gelar \\
the honour of knighthood by an adress to the King, during & kebangsawanan dalam masa jabatannya sebagai walikota." (43/TL- \\
his mayoralty." (43/SL-A/P.14) & B/H.29)
\end{tabular} \\
\hline
\end{tabular}

\section{Pembahasan:}

Data nomor 1, nama King dihilangkan dan tidak muncul dalam versi terjemahan bahasa sumber. The King dalam budaya sumber adalah ungkapan yang digunakan untuk menegaskan kehormatan ksatria salah satu tokoh dalam novel tersebut, yaitu Sir William Lucas. Cara penerjemah menghilangkan atau menerapkan strategi omission dari teks sumber King dan menerjemahkannya menjadi 'masa jabatannya' dianggap sebagai strategi untuk meminimalkan rasa asing atau foreignisasi dalam teks sasaran. Di sisi lain, peniadaannya dalam novel Pride and Prejudice versi Bahasa Indonesia telah memberikan pengaruh terhadap ideologi domestikasi yang menyatakan bahwa terjemahan sebaiknya mengutamakan keterbacaan teks untuk pembaca sasaran. Terjemahan yang dapat memenuhi selera dan harapan pembaca dianggap sebagai terjemahan yang betul, berterima, dan baik sesuai dengan latar belakang budaya masyarakat sasaran dengan menggunakan kata-kata atau istilah yang diterjemahkan ke dalam Bsa (Lörscher, 2012).

\section{2) Heaven}

\begin{tabular}{|l|l|}
\hline \multicolumn{1}{|c|}{ Bsu } & \multicolumn{1}{|c|}{ Bsa } \\
\hline $\begin{array}{l}\text { Would to Heaven that anything could be either said or } \\
\text { done in my part that might offer consolation to such } \\
\text { distress. (212/SL-A/P.260) }\end{array}$ & $\begin{array}{l}\text { Seandainya ada yang bisa kukatakan atau kulakukan untuk } \\
\text { meredakan kesedihanmu! (212/TL-B/H.414) }\end{array}$ \\
\hline
\end{tabular}

Pembahasan:

Data nomor 2, nama Heaven juga tidak diterjemahkan ke dalam bahasa sasaran. Menurut Kamus Oxford, Heaven didefinisikan sebagai: 1) tempat yang dipercaya sebagai rumah Tuhan dan orang-orang baik setelah kematian; 2) tempat atau keadaan kebahagiaan yang besar; 3) Tuhan. Namun, penerjemah menganggap istilah Heaven dalam teks sumber digunakan sebagai 
ungkapan untuk menyampaikan ucapan kepada karakter lain secara mendalam atau untuk mendramatisir ucapan tersebut. Selain itu, penghilangan atau strategi omission dalam istilah ini tidak mempengaruhi bahasa sasaran karena penerjemah menyampaikan maknanya dengan baik dalam bahasa sasaran - meskipun mungkin tidak sedalam bahasa sumber (Ningsih, 2016). Jadi, jika penerjemah mengalihkan nama Heaven menjadi 'surga', maka akan terkesan aneh karena tidak sesuai dengan maksud yang ingin disampaikan oleh penulis. Oleh sebab itu, penghilangan dianggap perlu jika nama menjadi tidak relevan atau tidak memiliki arti khusus dalam bahasa sasaran. Selanjutnya, penerapan strategi omission memberikan pengaruh terhadap ideologi domestikasi yakni penerjemah mengalihkan kata heaven menjadi 'seandainya' agar pembaca dapat menangkap maksud yang ingin disampaikan dalam teks tersebut.

b. Domestikasi melalui Strategi Localization

1) Colonel Millar

\begin{tabular}{|c|l|}
\hline \multicolumn{1}{|c|}{ Bsu } & \multicolumn{1}{|c|}{ Bsa } \\
\hline $\begin{array}{l}\text { "I am sure", said she, "I cried for two days together } \\
\text { when Colonel Millar's regiment went away. I thought I } \\
\text { should have masih ingat," katanya, "Aku menangis selama dua hari dua } \\
\text { malam ketika pasukan Kolonel Miller pergi. Hatiku hancur } \\
\text { berkeping-keping." (184/TL-B/H.348) }\end{array}$ \\
\hline
\end{tabular}

Pembahasan:

Data nomor 1, nama Colonel Millar dialihkan ke teks bahasa sasaran menjadi Kolonel Miller. Perhatikan bahwa penerjemah menerjemahkan nama dari bahasa sumber dengan terjemahan literal ke dalam bahasa sasaran. Namun demikian, terdapat sedikit perubahan pada teks tersebut sehingga teks tersebut wajar secara fonetik bahasa sasaran. Cara penerjemah mengubah huruf $\mathrm{C}$ menjadi $\mathrm{K}$ di Kolonel dan huruf a menjadi e di Miller telah membawa makna alami dan wajar dari bahasa sasaran ke pembaca sasaran (Ningsih, 2016). Dengan demikian, strategi penerjemahan Localization ini memberi efek domestikasi pada istilah yang diterjemahkan.

\section{c. Domestikasi melalui Strategi Transformation}

1) Monday

\begin{tabular}{|l|l|}
\hline \multicolumn{1}{|c|}{ Bsu } & \multicolumn{1}{|c|}{ Bsa } \\
\hline $\begin{array}{l}\text { "that he came down on Monday in a chaice and four to } \\
\text { see the place" (07/SL-A/P.1) }\end{array}$ & $\begin{array}{l}\text { "bahwa dia datang Senin lalu dengan kereta yang ditarik empat ekor } \\
\text { kuda untuk melihat-lihat tempat itu" (07/TL-B/H.8) }\end{array}$ \\
\hline
\end{tabular}

Pembahasan:

Monday diterjemahkan ke dalam bahasa sasaran menggunakan strategi transformation.

Nama hari diganti dengan padanan yang lebih sesuai dalam bahasa sasaran (Ningsih, 2016). Dengan demikian, kata Monday dapat diterjemahkan menjadi Senin melalui strategi pengalihan atau transformation. Pilihan strategi transformation ini membuat teks terjemahan lebih wajar dibaca dalam bahasa sasaran, sehingga memberikan efek ideologi domestikasi.

2) Scotch and Irish

\begin{tabular}{|l|l|}
\hline \multicolumn{1}{|c|}{ Bsu } & \multicolumn{1}{|c|}{ Bsa } \\
\hline "[...] and Mary, at the end of the long concerto, was glad to & "[..] dan Mary, diakhir conserto panjangnya, dengan bangga \\
purchase praise and gratitude by Scotch and Irish airs, & menerima pujian dan sambutan bergaya Skotlandia dan Irlandia, \\
{$[\ldots] "(55 / \mathrm{SL}-\mathrm{A} / \mathrm{P} .22)$} & {$[\ldots] "(55 / \mathrm{TL}-\mathrm{B} / \mathrm{H} .40)$} \\
\hline
\end{tabular}

Pembahasan:

Scotch, menurut Merriam-Webster Online Dictionary mengacu pada 1) untuk mengakhiri; 2) rakyat Skotlandia; 3) yang berhubungan dengan Skotlandia atau rakyatnya. Dalam novel, istilah itu disebut sebagai cara orang memberi penghormatan yakni menerapkan gaya Scotch dan Irish ways terhadap penampilan gadis keluarga Bennets. Meskipun penerjemah menerjemahkan makna Scotch dengan Scotland (Skotlandia, diterjemahkan) dan Irish menjadi Irland (Irlandia, diterjemahkan), arti teks tersebut tidak berubah karena penerjemah juga menambahkan styled (gaya, diterjemahkan) untuk menekankan arti sebenarnya dari teks sumber (Ningsih, 2016). Dengan demikian, makna yang diinginkan dari teks sumber dapat tersampaikan dengan cara yang wajar melalui strategi transformation atau pengalihan. Lebih lanjut, strategi ini memberikan pengaruh ideologi domestikasi. 


\begin{tabular}{|l|l|}
\hline \multicolumn{1}{|c|}{ Bsu } & \multicolumn{1}{|c|}{ Bsa } \\
\hline $\begin{array}{l}\text { “... where it shall be my earnest endeavor to demean myself } \\
\text { with grateful respect towards her Ladyship,..." (92/SL- } \\
\text { A/P.58) }\end{array}$ & $\begin{array}{l}\text { "Ditempat itulah, Saya akan mengabdikan diri kepada beliau,..." } \\
(92 / \text { TL-B/H.99) }\end{array}$ \\
\hline
\end{tabular}

Pembahasan:

Data nomor 3, nama Ladyship juga diubah dalam bahasa sasaran. Istilah Ladyship dalam bahasa sumber adalah ungkapan sopan yang merujuk pada salah satu tokoh yang pangkatnya tinggi dan terhormat. Penerjemah menggunakan istilah 'Beliau' dalam bahasa sasaran yang penggunaannya serupa dalam bahasa sumber untuk menyapa orang-orang yang tinggi dan terhormat. Penerjemah juga menggunakan istilah 'Beliau' dalam bahasa sasaran yang digunakan untuk menyebut seseorang dengan sopan (Ningsih, 2016). Strategi transformation atau pengalihan yang diterapkan oleh penerjemah ini dianggap tepat oleh peneliti, karena konteks tuturannya cocok antara Bahasa Sumber dan Bahasa Sasaran sehingga maksud yang disampaikan dapat dengan mudah dipahami pembaca. Dengan demikian, hal ini memberikan pengaruh ideologi domestikasi pada teks.

\section{d. Domestikasi melalui Strategi Creation}

1) The Bell

\begin{tabular}{|l|l|}
\hline \multicolumn{1}{|c|}{ Bsu } & \multicolumn{1}{|c|}{ Bsa } \\
\hline $\begin{array}{l}\text { “...Where shall you change horses? -Oh! Bromley, of } \\
\text { course, -If you mention my name at the Bell, you will attend } \\
\text { to." (171/SL-A/P.200) }\end{array}$ & $\begin{array}{l}\text { Jika kalian menyebutkan nama saya kepada petugasnya, kalian akan } \\
\text { mendapatkan pelayanan prima.” (171/TL-B/H.323) }\end{array}$ \\
\hline
\end{tabular}

Pembahasan:

Data nomor 1, penerjemah menggunakan 'Petugasnya' sebagai versi terjemahan dari the Bell yang tidak memiliki kesamaan arti dengan teks aslinya dalam bahasa sumber. The Bell dalam bahasa sumber mengacu pada benda logam berlubang berbentuk seperti cangkir yang mengeluarkan bunyi berdering saat dipukul oleh sesuatu yang keras. Penerjemah menggunakan istilah 'Petugasnya' dalam bahasa sasaran secara tersirat dinyatakan dalam versi aslinya (Ningsih, 2016). Menurut peneliti, penerjemah menggunakan istilah 'Petugasnya' yaitu orang yang berdiri di belakang meja resepsionis tempat the Bell biasanya berada - untuk mengubah kata the Bell agar tidak membingungkan pembaca sasaran. Dengan demikian, penerapan strategi creation tersebut melalui kreasi atau penciptaan dari si penerjemah, sehingga dapat memudahkan pembaca menangkap pesan teks yang ingin disampaikan, hal ini berdampak pada ideologi domestikasi.

\section{2) The Regular}

\begin{tabular}{|l|l|}
\hline \multicolumn{1}{|c|}{ Bsu } & \multicolumn{2}{|c|}{ Bsa } \\
\hline “...in considering the removal from that corps as highly & "Dan, kurasa kau akan setuju denganku bahwa dia harus seceparnya \\
advisable, both on his account and my niece's. Mr. & melakukan itu demi dirinya sendirian dan keponakanku. Mr \\
Wickman intends to go into the Regular, and among his & Wickman sendiri berniat untuk pindah, dan diantara teman- \\
former friends, there are still some who are able and willing & temannya, masih ada beberapa orang yang mampu dan mau \\
to assist him in the army." (228/SL-A/P.293) & memberinya pertolongan untuk karir militernya." (228/TL-B/H.467)
\end{tabular}

Pembahasan:

Data nomor 2, nama the Regular diterjemahkan ke dalam bahasa sasaran sebagai 'pindah' menggunakan strategi creation. Istilah the Regular dalam bahasa sumber, ketika makna ditulis, mengacu pada anggota tentara negara yang tidak tetap. Alih-alih menerjemahkan kata demi kata, penerjemah mempertimbangkan makna tersirat dari istilah the Regular dan memutuskan bahwa berdasarkan seluruh kalimat di atas, maka dapat diterjemahkan menjadi 'pindah' yakni terjemahan yang sesuai dalam bahasa sasaran. Penerjemah memilih creation sebagai strategi untuk menerjemahkan istilah agar tidak terdengar asing bagi pembaca sasaran (Ningsih, 2016). Selain itu, pilihan penerjemah ini, menurut peneliti, tidak mengubah makna kalimat karena si penerjemah menciptakan atau membuat kreasi istilah tersebut tanpa mengubah makna, namun bentuk yang diubah. Dengan demikian, strategi creation dinilai memberikan efek domestikasi pada teks.

\section{e. Domestikasi melalui Strategi Globalization}

Strategi penerjemahan globalization akan memungkinkan peralihan istilah budaya secara khusus menjadi istilah umum dalam membuat kata mudah dipahami oleh pembaca khalayak dari berbagai latar 
belakang budaya yang lebih luas (Shirinzadeh et al., 2014). Strategi ini dianggap sebagai bentuk domestikasi. Namun, seiring berjalannya penelitian, para peneliti tidak menemukan terjemahan proper noun yang diklasifikasikan dalam strategi ini.

Tabel 1. Ideologi penerjemahan Proper Noun melalui Strategi Penerjemahan yang digunakan penerjemah

\begin{tabular}{|c|c|c|c|c|c|}
\hline \multirow{2}{*}{ No. } & \multicolumn{3}{|c|}{ Proper Nouns } & \multicolumn{2}{|c|}{ Tipe-tipe Ideologi Penerjemahan } \\
\hline & Kode & Bahasa Sumber (Bsu) & Bahasa Sasaran (Bsa) & Foreignization & Domestication \\
\hline 1 & 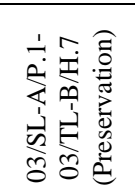 & $\begin{array}{l}\text { "My dear Mr. Bennet," said his } \\
\text { lady to him one day, "have you } \\
\text { heard that Netherfield Park is let } \\
\text { at last?" }\end{array}$ & $\begin{array}{l}\text { "Suamiku Mr. Bennet tersayang," kata } \\
\text { Mrs. Bennet kepada suaminya pada } \\
\text { suatu hari, "sudahkah kau mendengar } \\
\text { bahwa akhirnya ada yang menyewa } \\
\text { Netherfield Park?" }\end{array}$ & $\sqrt{ }$ & \\
\hline 2 & 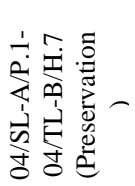 & $\begin{array}{l}\text { "But it is," returned she; "for } \\
\text { Mrs. Long has just been here, } \\
\text { and she told me all about it." }\end{array}$ & $\begin{array}{l}\text { "Tetapi itulah kenyataannya," jawab } \\
\text { Mrs. Bennet, "karena Mrs. Long baru } \\
\text { saja dari sana dan dia } \\
\text { menceritakannya kepadaku." }\end{array}$ & $\sqrt{ }$ & \\
\hline 3 & 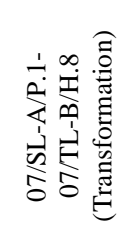 & $\begin{array}{l}\text { "That he came down on Monday } \\
\text { in a choice and four to see the } \\
\text { place." }\end{array}$ & $\begin{array}{l}\text { "Bahwa dia datang Senin lalu dengan } \\
\text { kereta yang ditarik empat ekor kuda } \\
\text { untuk melihat-lihat tempat itu." }\end{array}$ & & $\sqrt{ }$ \\
\hline 4 & 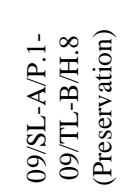 & $\begin{array}{l}\text { "That he is to take possession } \\
\text { before Michaelmas, and some of } \\
\text { his servants are to be in the } \\
\text { house by the end of next week." }\end{array}$ & $\begin{array}{l}\text { "Dia akan menempati tempat itu } \\
\text { sebelum perayaan Michaelmas, dan } \\
\text { beberapa pelayannya akan tiba disana } \\
\text { pada akhir minggu depan." }\end{array}$ & $\sqrt{ }$ & \\
\hline 5 & 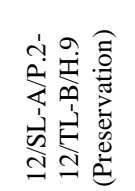 & $\begin{array}{l}\text { "Sir William and Lady Lucas are } \\
\text { determined to go, merely on that } \\
\text { account, for in general, you know } \\
\text { they visit no newcomers." }\end{array}$ & $\begin{array}{l}\text { "Sir William dan Lady Lucas sudah } \\
\text { bertekat akan pergi hanya untuk } \\
\text { urusan itu; kau tahu sendiri biasanya } \\
\text { mereka tidak pernah mengunjungi } \\
\text { pendatang baru." }\end{array}$ & $\sqrt{ }$ & \\
\hline 6 & 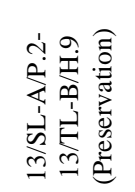 & $\begin{array}{l}\text { "Sir William and Lady Lucas are } \\
\text { determined to go, merely on that } \\
\text { account, for in general, you know } \\
\text { they visit no newcomers." }\end{array}$ & $\begin{array}{l}\text { "Sir William dan Lady Lucas sudah } \\
\text { bertekat akan pergi hanya untuk } \\
\text { urusan itu; kau tahu sendiri biasanya } \\
\text { mereka tidak pernah mengunjungi } \\
\text { pendatang baru." }\end{array}$ & $\sqrt{ }$ & \\
\hline 7 & 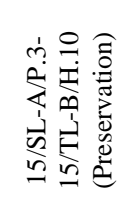 & $\begin{array}{l}\text { "[...] and I am sure she is not } \\
\text { half so handsome as Jane," }\end{array}$ & $\begin{array}{l}\text { "[...] kecantikannya tidak sampai } \\
\text { separuh dari kecantikan Jane," }\end{array}$ & $\sqrt{ }$ & \\
\hline 8 & 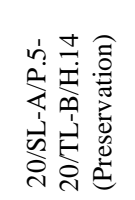 & $\begin{array}{l}\text { Mary wished to say something } \\
\text { very sensible but knew not how. }\end{array}$ & $\begin{array}{l}\text { Mary berharap bisa mengatakan } \\
\text { sesuatu yang cerdas, tapi dia tidak } \\
\text { tahu harus berkata apa. }\end{array}$ & $\sqrt{ }$ & \\
\hline 9 & 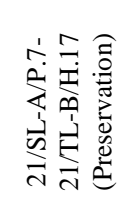 & $\begin{array}{l}\text { She could not imagine what } \\
\text { business he could have in town so } \\
\text { soon after he arrived in } \\
\text { Hertfordshire. }\end{array}$ & $\begin{array}{l}\text { Dia tidak mampu membayangkan } \\
\text { urusan apa yang telah menanti Mr. } \\
\text { Bingley di kota segera setelah } \\
\text { kedatangannya di Hertfordshire. }\end{array}$ & $\sqrt{ }$ & \\
\hline 10 & 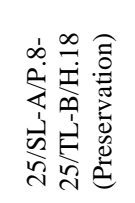 & $\begin{array}{l}\text { And not all his large estate in } \\
\text { Derbyshire could then save him } \\
\text { from having a most forbidding, } \\
\text { [...]. }\end{array}$ & $\begin{array}{l}\text { Dan tanah luasnya di Derbyshire } \\
\text { sekalipun tidak sanggup menutupi } \\
\text { perangai terburuknya. }\end{array}$ & $\sqrt{ }$ & \\
\hline
\end{tabular}


"Mrs. Bennet had seen her eldest daughter much admired by the

으 즈 Then the two third he danced

그를

ले

党華

"[...] when he was tempted by an accidental recommendation to look at Netherfield House."

Within the short walk of ㅎํ Longbourn lived a family with \pm ํ.

particularly intimate.
"Sir William Lucas had been ذे กิ formerly in trade in Meryton, ค.

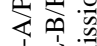

fortune, and risen to the honor of knighthood by an address to the King, during his mayoralty."

Denominated from that period 느 고 을 Lucas Lodge.

16

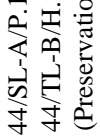

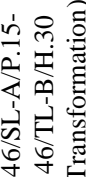

That the Miss Lucases and Miss Bennets should meet to talk over a ball was necessary.
"Mrs. Bennet melihat bahwa putri sulungnya paling dikagumi oleh rombongan Netherfield."

Setelah itu, dia berdansa dengan Miss King

“[...] ketika sebuah penawaran yang tidak terduga membawanya ke Netherfield House"

Tak jauh dari Longbourn, tinggalah sebuah keluarga yang akrab dengan keluarga Bennet.
"Sir William Lucas dahulu berdagang di Merython. Disana, dia mendapatkan cukup banyak kekayaan dan dianugrahi gelar kebangsaan dalam masa jabatannya sebagai walikota."

Rumah itu dinamai Lucas Lodge sejak saat itu.

Gadis-gadis Lucas merasa perlu bertemu dengan gadis-gadis Bennet untuk membahas tentang pesta dansa.
"Yes, these four evenings have กิ ธิ enabled them to ascertain that $\xi$ in they both like Vingt-un better 's

ते है

"Yes, these four evenings have ₹ enabled them to ascertain that

语 they both like Vingt-un better

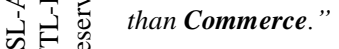

हो थे है

"[...] and Mary, at the end of the กิ \& $\overbrace{i}^{\mathbb{N}}$ purchase praise and gratitude by Scotch and Irish airs, [...]",
"Ya, keempat malam itu telah berhasil meyakinkan mereka bahwa mereka lebih menyukai permainan kartu Vingt-un daripada Commerce."

"Ya, keempat malam itu telah berhasil meyakinkan mereka bahwa mereka lebih menyukai permainan kartu Vingt-un daripada Commerce."

“[...] dan Mary, diakhir conserto panjangnya, dengan bangga menerima pujian dan sambutan bergaya Skotlandia dan Irlandia, [...]" 
Tabel 2. Hasil Ideologi Penerjemahan Proper Nouns melalui Strategi Penerjemahan yang digunakan penerjemah

\begin{tabular}{cccc}
\hline No. & Ideologi Penerjemahan & Frekuensi & Persentase \\
\hline 1 & Foreignization & 164 & $\mathbf{6 5 , 3 3 \%}$ \\
2 & Domestication & 87 & $\mathbf{3 4 , 6 7 \%}$ \\
& & & $\mathbf{1 0 0 \%}$ \\
\hline
\end{tabular}

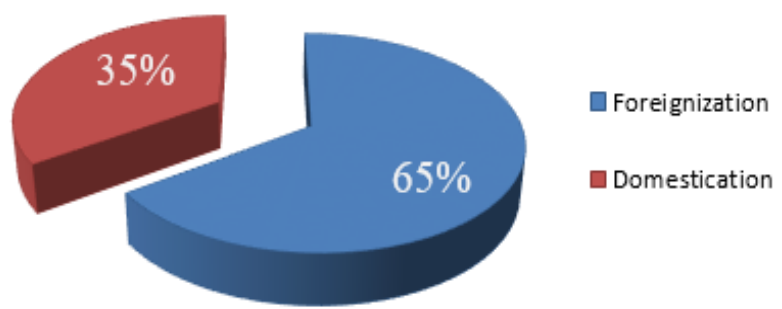

Gambar 2. Ideologi Penerjemahan Proper Nouns melalui Strategi Penerjemahan yang digunakan penerjemah

Ideologi penerjemahan yang ditemukan dalam novel ini adalah foreignization (foreignisasi) dan domestication (domestikasi). Hasil penelitian dapat diuraikan, dari 60 data proper nouns yang ditemukan dalam novel, 167 data $(66,53 \%)$ ditemukan ideology foreignization, sedangkan data $(33,47 \%)$ ditemukan ideologi domestikasi. Setiap ideologi berbagi strategi tertentu sesuai dengan efek yang ditemukan dalam Bahasa Sasaran. Persentase ideologi foreignisasi diwakili dengan 66, 53\% data. Sisa data lainnya dimasukkan ke dalam lampiran. Data ini diolah dengan mengamati strategi terjemahan yang digunakan oleh penerjemah. Data yang diklasifikasikan dalam ideologi foreignisasi diterjemahkan menggunakan strategi preservation. Strategi ini dipertimbangkan oleh penerjemah untuk menjaga dan mempertahankan orisinalitas novel, menjaga budaya sumber yang ditulis dalam novel, serta menghadirkan suasana nyata dalam novel aslinya kepada pembaca sasaran. Dengan demikian, strategi preservation banyak digunakan. Persentase ideologi domestikasi diwakili dengan 33,47\% data. Data yang diklasifikasikan dalam ideologi domestikasi diterjemahkan menggunakan localization, omission, transformation, globalization, dan creation. Localization digunakan untuk membuat nama terdengar lebih wajar dalam Bahasa Sasaran, namun, strategi localization hanya digunakan dalam satu data. The omission tersebut digunakan oleh penerjemah untuk mengurangi terjemahan yang tidak perlu. Strategi Transformation, di sisi lain, digunakan oleh penerjemah proper noun yang memiliki arti setara dalam Bahasa Sasaran. Globalization merupakan penyederhanaan Bahasa Sumber ketika diterjemahkan ke dalam bahasa sasaran yang dianggap lebih mudah dipahami oleh pembaca sasaran. Creation adalah ketika penerjemah memilih istilah penerjemahan yang sama sekali berbeda dalam Bahasa Sasaran serta tidak ada dalam Bahasa Sumber dan relevan dengan makna teks yang dimaksudkan.

\section{Simpulan}

Pada bagian ini, peneliti ingin memberikan beberapa simpulan sebagai berikut:

1. Analisis ideologi penerjemahan proper nouns dalam novel Pride and Prejudice menggunakan pendekatan komparatif berdasarkan teori proses penerjemahan dikemukakan oleh Catford dan Nida yang menggantikan materi tekstual dalam Bahasa Sumber dengan padanannya dalam Bahasa Sasaran. Sementara itu, ditemukan kecenderungan ideologi menerjemahkan proper noun pada novel ini dengan menerapkan tujuh strategi terjemahan yang digunakan oleh Shirinzadeh et al. (2014), peneliti menyimpulkan bahwa ideologi foreignization atau foreignisasi dominan digunakan oleh penerjemah sebesar 65, 33\% data proper noun foreignisasi. Misalnya, nama Mr. Bennet dipertahankan oleh penerjemah sebagai Mr. Bennet dalam bahasa sasaran alih-alih menggunakan Tuan Bennet. Hal ini 
memberikan efek foreignisasi pada teks yang diterjemahkan. Sedangkan, ideologi domestikasi sebesar 34, 67\% data proper noun, misalnya nama The Church of England diterjemahkan oleh penerjemah dengan padanannya dalam bahasa sasaran menjadi Gereja Inggris. Dengan demikian, istilah yang diterjemahkan memberikan efek ideologi domestikasi yang lebih wajar dalam Bahasa Sasaran. Berdasarkan hasil dan pembahasan yang telah diuraikan di atas, maka data mengenai foreignisasi lebih dominan ditemukan dalam penelitian ini, karena ideologi penerjemahan foreignisasi ini berorientasi pada BSu, yakni terjemahan yang akurat, berterima, dan mudah dipahami pembaca serta menginginkan kehadiran kebudayaan BSu pada hasil terjemahan. Foreignisasi menganggap tetap hadirnya kebudayaan asing dapat bermanfaat bagi pembaca sasaran. Fokus pada ideologi ini adalah adanya aspek kebudayaan asing yang diungkapkan dalam BSa. Contoh penerapan ideologi foreignisasi dalam penelitian ini adalah kata-kata Mr, Mrs yang tidak diterjemahkan, sebab dianggap pembaca Indonesia sudah tidak asing lagi dengan sapaan tersebut.

2. Ideologi penerjemahan yang ditemukan dalam novel ini digolongkan menjadi dua jenis yaitu: foreignization dan domestication. Foreignization memegang bahasa dan budaya sumber dalam Bahasa Sasaran dengan maksud penerjemah memilih mempertahankan konsep-konsep atau istilah yang ada pada BSu. Misalnya, nama Netherfield Park yang dipertahankan menjadi Netherfield Park, bukan Taman Netherfield. Sedangkan, domestikasi mendekatkan budaya sasaran dengan Bahasa Sasaran dan budaya sasaran. Misalnya nama the Bennets diterjemahkan menjadi Keluarga Bennet yang terdengar wajar dan familiar di Bahasa Sasaran sehingga berterima di kalangan pembaca BSa.

\section{Dafatar Rujukan}

Akbari, Monireh. "The role of culture in translation." Journal of Academic and Applied studies 3.8 (2013): 13-21.

Al Fattah, Habib, and M. Muamaroh. A Translation Shift Analysis of Noun in the Bilingual Wow ComicsThe Little Prince. Diss. Universitas Muhammadiyah Surakarta, 2017.

Barnes, Scott. "Proper noun in conversation: A description of how a man constructed referencing turns." Aphasiology 27.1 (2013): 1-19.

Boase-Beier, Jean. Stylistic approaches to translation. Routledge, 2014.

Cascallana, Belén González. "Translating Cultural Intertextuality in." Children's literature in translation: Challenges and strategies (2014): 97.

Devianty, Rina. "Bahasa sebagai cermin kebudayaan." Jurnal tarbiyah 24.2 (2017).

Dewi, K. D. "Penerjemahan Dajare Komik Kuroko No Basket Karya Tadatoshi." (2016): 92-99.

Eagleton, Terry. The English novel: an introduction. John Wiley \& Sons, 2013.

Farahani, Vasheghani, and Arezo Mokhtari. "An analysis of cultural specific items in English translation of "Blind owl"-domestication vs. foreignization." Journal of Applied Linguistics and Language Research 3.4 (2016): 308-324.

Gunawan, Imam. "Metode penelitian kualitatif." Jakarta: Bumi Aksara 143 (2013).

Lörscher, Wolfgang. "Bilingualism and translation competence." (2012).

Munday, Jeremy. Introducing translation studies: Theories and applications. Routledge, 2016.

Ningsih, Ester Susetya. "The Translation Ideology Based on the Translation Strategies Applied in the Translation of the Proper Nouns in Colombus and Vizinni's House Of Secrets Novel." Sastra Inggris-Quill 5.5 (2016): 352-369.

Nugroho, Raden Arief. "The Use of Microstrategies in Students' Translation: A Study on Classroom Translation Process and Product." Prasasti: Journal of Linguistics 2.1 (2016).

Oittinen, Riitta. "On the Ethics of Translating for Children." Children's literature in translation: Challenges and strategies 35 (2014).

O'Sullivan, Emer. "Children's literature and translation studies." The Routledge handbook of translation studies. Routledge, 2013. 469-481.

Saraswati, Ria, and Ratna Dewanti. "Translation Technique, Ideology, and Culture." Talent Development \& Excellence 12.1 (2020).

Shirinzadeh, Seyed Alireza, and Tengku Sepora Tengku Mahadi. "Translating Proper Nouns: A Case Study on English Translation of Hafez's Lyrics." English Language Teaching 7.7 (2014): 8-16.

Shiyab, Said. A textbook of translation: Theoretical and practical implication. Vol. 6. Garant UitgeversArabic Translators International (= ATI); Antwerpen, 2012. 
Umam, Khairul. "The Development of E-Learning System on Language Learning For English Departement Faculty of Syiah Kuala University." Jurnal Peluang 4.2 (2015).

Venuti, Lawrence, ed. Rethinking translation: Discourse, subjectivity, ideology. Vol. 2. Routledge, 2018.

Venuti, Lawrence. The translator's invisibility: A history of translation. Routledge, 2017.

Yang, Lijun. "The Application of Foreignization and Domestication in the Translation." International Conference on Education, Language, Art, and Intercultural Communication (ICELAIC-14). Atlantis Press, 2014.

Zarei, Rouhollah, and Somayeh Norouzi. "Proper nouns in translation." International journal of applied linguistics and English literature 3.6 (2014): 152-161. 